\title{
Experiência de educação em saúde bucal em escola de educação infantil na República de Cabo Verde, África
}

Oral health education experience at a Childhood School in Republic of Cape Verde, Africa Experiencia en educación de salud oral en un preescolar en la Republica de Cabo Verde, África

\author{
Andreia Tairine Gonçalves CARDOSO ${ }^{1}$ \\ Elsa Patrícia Alves Spínola CORREIA ${ }^{2}$ \\ Dionísio Eduardo Gonçalves FERNANDES ${ }^{3}$ \\ João Pedro Justino de Oliveira LIMÍRIO \\ Maria Cristina Rosifini ALVES REZENDE ${ }^{5}$
}

${ }^{1}$ Graduanda em Odontologia, Universidade Estadual Paulista (UNESP), Faculdade de Odontologia de Araçatuba, 16015-050 Araçatuba-SP, Brasil ${ }^{2}$ Diretora Pedagógica, Escola de Educação Infantil Primeiros Passos, São Filipe, Ilha do Fogo, República de Cabo Verde, África

${ }^{3}$ Subdiretor Pedagógico, Patim, Ilha do Fogo, República de Cabo Verde, África

${ }^{4}$ Mestrando, Programa de Pós-Graduação em Odontologia, Universidade Estadual Paulista (UNESP), Faculdade de Odontologia de Araçatuba, 16015-050 Araçatuba-SP, Brasil ${ }^{5}$ Professora Associada, Universidade Estadual Paulista (UNESP), Faculdade de Odontologia de Araçatuba, 16015-050 Araçatuba-SP, Brasil

\section{Resumo}

Dados do Observatório de Saúde Africana (African Health Observatory), ligado à Organização Mundial de Saúde (World Health Organization) apontam elevada prevalência da cárie dentária, principalmente entre a população escolar de Cabo Verde, elencando a necessidade da priorização da promoção da saúde bucal e da prevenção das doenças bucais pela integração da saúde oral em outros programas tais como a formação de professores, educadores de infância e outros programas de responsabilidade na promoção de saúde. A literatura aponta que a educação em saúde bucal mostra alta eficiência na diminuição do risco à cárie dentária, de alta evolução em crianças na faixa de 0 a 6 anos de idade, e que a escola de educação infantil se mostra como local privilegiado para o desenvolvimento de programas de educação e prevenção em saúde bucal, uma vez que reúne crianças com e sem acesso aos cuidados odontológicos privados. Com base nessa perspectiva o objetivo deste trabalho foi descrever a experiência de educação em saúde bucal em escola privada de educação infantil em Cabo Verde, África.

Descritores: Educação Infantil; Educação em Saúde; Saúde Bucal.

\section{Abstract}

Data from the African Health Observatory, linked to the World Health Organization (World Health Organization), indicate a high prevalence of dental caries, especially among the Cape Verdean school population, highlighting the need to prioritize oral and oral health promotion. prevention of oral diseases by integrating oral health into other programs such as teacher training, early childhood educators and other health promotion responsibility programs. The literature points out that oral health education shows high efficiency in reducing the risk of dental caries, of high evolution in children between 0 and 6 years old, and that the preschool is a privileged place for development. of oral health education and prevention programs, as it brings together children with and without access to private dental care. Based on this perspective the objective of this paper was to describe the experience of oral health education in a private elementary school in Cape Verde, Africa.

Descriptors: Child Hearing; Health Education; Oral Health.

\section{Resumen}

Los datos del Observatorio Africano de la Salud, vinculados a la Organización Mundial de la Salud (Organización Mundial de la Salud), indican una alta prevalencia de caries dental, especialmente entre la población escolar de Cabo Verde, destacando la necesidad de priorizar la promoción de la salud oral y oral. prevención de enfermedades orales mediante la integración de la salud bucal en otros programas, como la capacitación de docentes, educadores de la primera infancia y otros programas de responsabilidad de promoción de la salud. La literatura señala que la educación en salud oral muestra una alta eficiencia en la reducción del riesgo de caries dental, de alta evolución en niños entre 0 y 6 años, y que el preescolar es un lugar privilegiado para el desarrollo. de programas de educación y prevención de salud bucal, ya que reúne a niños con y sin acceso a atención dental privada. En base a esta perspectiva, el objetivo de este trabajo fue describir la experiencia de la educación en salud bucal en una escuela primaria privada en Cabo Verde, África.

Descriptores: Crianza Del Niño; Educación en Salud; Salud Bucal.

\section{INTRODUÇÃO}

A República de Cabo Verde é um arquipélago com superfície terrestre de $4.033 \mathrm{~km}^{2}$ composto por 10 ilhas, das quais nove são habitadas e oito são ilhéus. Situada na costa ocidental africana, a cerca de 500 quilómetros a oeste do Senegal, a República de Cabo Verde é banhada pelo oceano atlântico, estendendo-se entre os paralelos $17^{\circ} 12,5^{\prime} \mathrm{e}$ $14^{\circ} 48^{\prime}$ de latitude norte e o meridiano $22^{\circ} 44^{\prime}$ e $25^{\circ}$ $22^{\prime}$ de longitude oeste de Greenwich. As ilhas de Cabo Verde, de origem vulcânica e elevada aridez meteorológica, estão divididas em dois grupos de ilhas: o grupo de Barlavento (Santo Antão, São Vicente, São Nicolau Sal e Boavista) e o grupo de Sotavento (Santiago, Maio, Fogo e Brava). Mostramse habitadas em três dela, sendo as outras montanhosas. A República de Cabo Verde tem clima tropical, dominado pelos ventos secos do nordeste e regista os menores índices de chuva do mundo, de julho a outubro, com ciclo de seca prolongado, além de escassez de recursos naturais marcante ${ }^{1}$.

Estima-se a população cabo-verdiana em 546.171 habitantes. A taxa de crescimento médio anual é da ordem de $1,2 \%$. A pirâmide etária tem mostrado uma significativa redução na população com menos de 14 anos e a esperança média de vida ao nascer é de 75 anos para homem e 78 anos para mulher. A Mortalidade infantil apurada em 2012 foi de 26,02 por mil nascimentos, ocupando a $108^{\circ}$ posição mundial ${ }^{2}$.

Dados do Observatório de Saúde Africana (African Health Observatory), ligado à Organização Mundial de Saúde (World Health Organization) apontam elevada prevalência da cárie dentária principalmente entre a população escolar de Cabo Verde, elencando a necessidade da priorização da promoção da saúde oral e da prevenção das doenças orais pela integração da saúde oral em outros programas (ex. formação de professores, educadores 
de infância e outros programas de responsabilidade na promoção de saúde) $)^{3}$.

Segundo Garbin et al. $^{4}$, em crianças, a educação em saúde bucal se mostra altamente eficiente na diminuição do risco à cárie dentária, a qual pode evoluir rapidamente nesta faixa etária, comprometendo a qualidade de vida da criança e de seus familiares 5 . Ademais, a escola de educação infantil se mostra como local privilegiado para o desenvolvimento de programas de educação e prevenção em saúde bucal, uma vez que reúne crianças com e sem acesso aos cuidados odontológicos privados ${ }^{6}$ Com base nessa perspectiva o objetivo deste trabalho foi descrever a experiência de educação em saúde bucal em escola privada de educação infantil em São Filipe, Ilha do Fogo, na República de Cabo Verde, África.

\section{RELATO DE EXPERIÊNCIA}

\section{- A escola}

A escola, pessoa jurídica de capital privado, atende 80 alunos, de 0 a 5 anos de idade, distribuídos em três salas de aula (Figura 1). Conta com uma pedagoga (educadora), cinco auxiliares pedagógicos, uma cozinheira e uma coordenadora pedagógica. $\mathrm{O}$ abastecimento de água potável contempla água fluoretada na localidade. Há efetivo controle por parte das autoridades governamentais no sentido de controle dos níveis de flúor na água de nascente de Encontro foi confirmada desde 1994 .

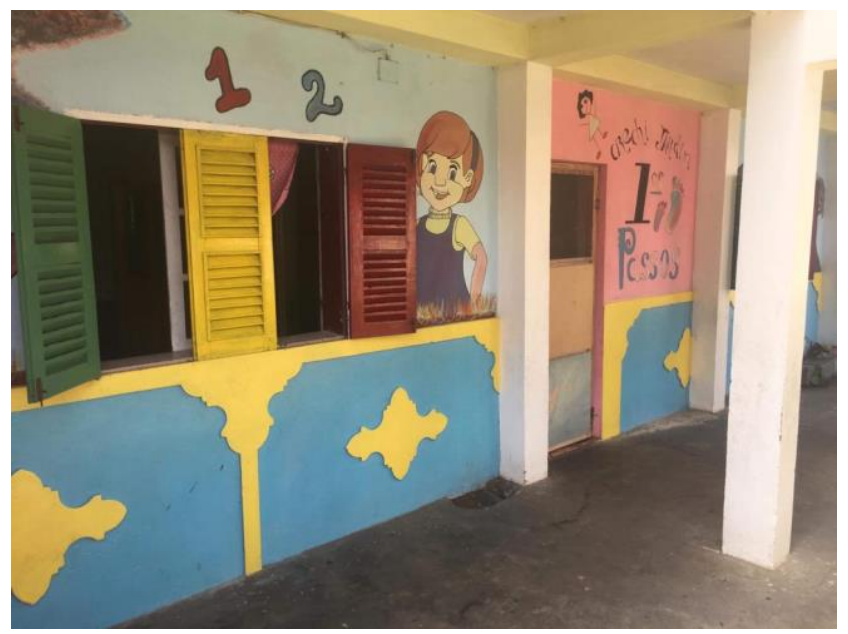

Figura 1: Ambiente escolar.

\section{- Como a escola faz a promoção da saúde}

As atividades de educação para a saúde bucal são realizadas por corpo docente treinado para instruir os alunos na promoção de saúde bucal. A escola conta com $\mathrm{x}$ alunos, $\mathrm{x}$ professores, $\mathrm{s}$ funcionários e $\mathrm{x}$ diretores.

A escola conta com local apropriado para realização de higiene bucal pelos alunos. As escovas dentárias, identificadas, são acondicionadas de forma cuidadosa a fim de se evitar a translocação bacteriana entre elas.

Periodicamente, um cirurgião-dentista visita a escola, realizando nessas visitas procedimentos de aplicação tópica de flúor por meio de bochechos. Outra atividade desenvolvida pelo profissional é a ministração de palestras educativas aos alunos.

- Ação dos educadores preparados para educação em saúde bucal na educação infantil

A escola privilegia estratégias nas quais os educadores em educação infantil ("educadores de infância") preparados para educação em saúde bucal, instruem quanto às práticas nutricionais corretas, com moderado consumo de sacarose. Ademais, após as refeições realizadas na escola, os educadores conduzem os alunos ao espaço coletivo reservado para higienização bucal (Figuras 1 e 2).

- Ação dos educadores junto aos familiares $e$ responsáveis

Os pais e responsáveis pelas crianças matriculadas na escola também são abrangidos pela educação em saúde bucal, na medida em que os educadores buscam aumentar a conscientização sobre o consumo consciente de açúcar e desenvolvimento de hábitos de higienização bucal. Além disso, sempre que os educadores detectam condição bucal desfavorável, pais ou responsáveis são comunicados sobre a necessidade de encaminhamento da criança para o cuidado necessário por cirurgião-dentista.

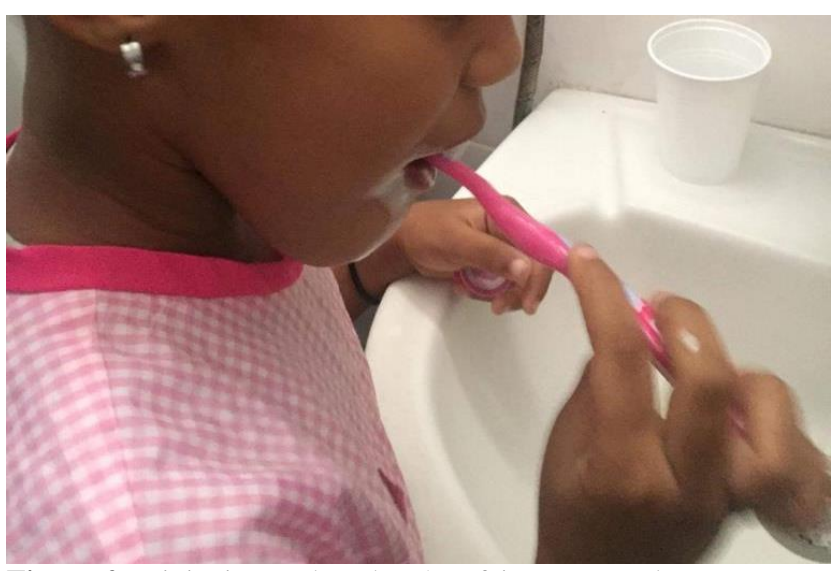

Figura 2: Higienização bucal após refeição na escola.

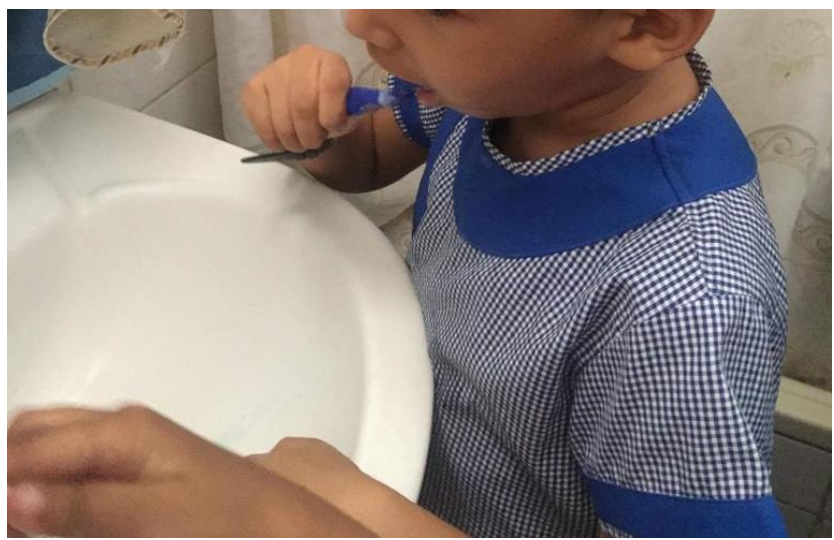

Figura 3: Higienização bucal após refeição na escola.

\section{DISCUSSÃO}

Segundo Paiva et al. ${ }^{7}$ o trabalho em equipe entre cirurgiões-dentistas e professores de educação infantil na divulgação de promoção em saúde bucal é 
fundamental no controle da cárie dentária nesta faixa etária. O professor está diariamente e por longo período com a criança, exercendo forte influência sobre o seu comportamento e formação de valores ${ }^{8}$.

Wyne et al. ${ }^{9}$ alertam que o sucesso de um programa educativo em saúde bucal, que o associe o trabalho conjunto de cirurgião-dentista e pedagogo, implica necessariamente na avaliação e revisão dos conhecimentos e atitudes dos professores de educação infantil, no que diz respeito à etiologia, prevenção e evolução da cárie dentária e da doença periodontal.

Também Ferreira et al. ${ }^{10}$ destacam o importante papel dos professores como parceiros em programas educativos e preventivos. Segundo os autores, na medida em que os professores convivem intensamente com os escolares, são atores importantes para o desenvolvimento de ações de promoção de saúde bucal.

Garbin et al. ${ }^{11}$ investigaram as opiniões e o conhecimento sobre saúde bucal em concluintes do curso de Pedagogia da cidade de Araçatuba, São Paulo, Brasil. Observaram que $86,8 \%$ dos futuros educadores acham que o professor deve atuar como educador em saúde bucal e 92,4\% consideram importante a sua integração com profissionais de saúde. Apenas 9\% responderam corretamente sobre o conceito de placa bacteriana e $34,8 \%$ sobre a cárie dentária, enquanto $67 \%$ e $83,7 \%$, responderam corretamente, respectivamente, sobre o surgimento da cárie e possibilidade de dentição saudável por toda a vida. Os autores concluíram que, embora esses futuros pedagogos tenham opiniões positivas em relação à educação em saúde bucal, seu conhecimento sobre a temática abordada é insatisfatório, considerando sua atuação futura como educadores e formadores de opinião.

Segundo Miller et al. ${ }^{12}$, ações educativas em saúde bucal podem contribuir para que os escolares alcancem autonomia nas práticas de higiene bucal, contribuindo para sua saúde e qualidade de vida.

Isso ganha grande importância se considerarmos que dados da Direção Nacional de Saúde apontam a cárie dentária como altamente prevalente na população cabo-verdiana, sendo uma das principais doenças que afeta escolares $(89,6 \%$ na faixa de 7 aos 15 anos), principalmente no meio urbano, levando o índice CPO-D do arquipélago para o patamar de 4,5.

Ademais, a pouca informação da população adulta da República de Cabo Verde sobre os cuidados básicos de higiene bucal (também aferida pela Direção Nacional de Saúde) aliada ao pequeno número de cirurgiões-dentistas em exercício (56 profissionais em 2010), também ressaltam o importante papel do "educador de infância" na formação de indivíduos que promovam a saúde bucal para si e seus familiares.

\section{CONCLUSÃO}

Diante do relato apresentado, enfatiza-se o papel da escola como parceira eficiente na formação de uma cultura de prevenção de doenças bucais, na medida em que atua como importante agente transmissor de informações sobre saúde bucal, controle de açúcar na dieta e hábitos necessários para higiene da boca.

\section{REFERÊNCIAS}

1. Ministério da Saúde. Plano Multisectorial de Prevenção e Controlo de Doenças Não Transmissíveis de Cabo-Verde. Cidade da Praia, Junho de 2014 , Cabo Verde. Disponível em: https://www.iccpportal.org/system/files/plans/CPV_B3_PMPCDN T_VFINAL_02.07.2014.pdfAcesso em:

2. Country Meters. Disponível em: https://countrymeters.info/pt/Cape_Verde. Acesso em 03 de janeiro de 2019.

3. Who-Afro. African Health Observatory. Data \& statistics health situation analysis african health monitor atlas publications. Disponível em: http://www.aho.afro.who.int/profiles_information/ index.php/Cape_Verde:Oral_health_and_noma/pt. Acesso em 03 de janeiro de 2019.

4. Garbin C, Garbin A, Dos Santos K, Lima D. Oral health education in schools: promoting health agents. Int J Dent Hyg. 2009;7(3):212-16.

5. Rozier RG, Sutton BK, Bawden JW, Haupt K, Slade GD, King RS. Prevention of early childhood caries in North Carolina medical practices: implications for research and practice. $\mathrm{J}$ Dent Educ. 2003; 67(8):876-85.

6. Loupe MJ, Frazier PJ. Knowledge and attitudes of schoolteachers toward oral health programs and preventive dentistry. J Am Dent Assoc. 1983;107(2):229-34.

7. Paiva SM, Gonçalves DHA, Péret LRCA. Promoção de saúde bucal: programa implantado em escolares da região leste de Belo Horizonte. Rev Saúde em Debate. 1992;37:36-9.

8. Santos PA, Rodrigues JÁ, Garcia PPNS. Avaliação do conhecimento dos professores do ensino fundamental de escolas particulares sobre saúde bucal. Rev Odontol UNESP. 2002; 31(2):205-14.

9. Wyne AH, Al-Ghorabi BM, Al-Asiri YA, Khan NB. Caries prevalence in Saudi primary schoolchildren of Riyadh and their teachers' oral health knowledge, attitude and practices. Saudi Med J. 2002;23(1):77-81.

10.Ferreira JMS, Massoni ACLT, Forte FDS, Sampaio FC. The knowledge of oral health of undergraduate students of Pedagogy. Interface (Botucatu). 2005;9(17):381-88.

11.Garbin CAS, Garbin AJI, Santos KT, Hidalgo LRC, Moimaz SAS. Conhecimento sobre saúde 
bucal por concluintes de pedagogia. Trab Educ Saúde. 2012;10(3):453-62.

12. Miller FY, Lautar CJ, Meyer JM, Summers DG. Achieving autonomy in dental hygiene practice through a school-based oral health program. J Den Hyg. 2006;80(1):28-8

\section{CONFLITO DE INTERESSES}

Os autores declaram não haver conflitos de interesse.

AUTOR PARA CORRESPONDENCIA

Maria Cristina Rosifini Alves Rezende

cristina.rosifini@unesp.br

Submetido em 28/04/2019

Aceito em 15/05/2019 